\title{
Does simulation-based training facilitate the integration of human anatomy with surgery? A report of a novel Surgical Anatomy Course
}

\author{
K. Torres ${ }^{1}$, M. Denisow-Pietrzyk ${ }^{1}$, Ł. Pietrzyk ${ }^{1}{ }^{3}$, R. Maciejewski², A. Torres ${ }^{2}$ \\ ${ }^{1}$ Department of Didactics and Medical Simulation, Chair of Human Anatomy, Medical University of Lublin, Poland \\ ${ }^{2}$ Chair and Department of Human Anatomy, Medical University of Lublin, Poland \\ ${ }^{3}$ Department of General, Oncological, and Minimally Invasive Surgery, $1^{\text {st }}$ Military Clinical Hospital with the Outpatient \\ Clinic, Lublin, Poland
}

[Received: 4 June 2017; Accepted: 30 August 2017]

Background: Knowledge of gross anatomy, as a basic core subject, is fundamental for medical students and essential to medical practitioners, particularly for those intending a surgical career. However, both medical students and clinical teachers have found a significant gap in teaching basic sciences and the transition into clinical skills. The authors present a Surgical Anatomy Course developed to teach the anatomical basis of surgical procedures with particular emphasis on laparoscopic skills while incorporating medical simulation.

Materials and methods: An evaluation of the students' satisfaction of the Surgical Anatomy Course was completed using a mix of multiple choice and open-ended questions, and a six-point Likert Scale. Questions were asked about the students' perceived improvement in surgical and laparoscopic skills. Manual skills were assessed using a laparoscopic simulator.

Results: Both evaluation of the course structure and the general impression of the course were positive. Most students believed the course should be an integral part of a modern curriculum. The course supported the traditional surgical classes and improved anatomical knowledge and strengthened students' confidentiality and facilitated understanding and taking surgical rotations.

Conclusions: A medical course combining the practical learning of anatomy and surgical-based approaches will bring out the best from the students. Medical students positively evaluated the Surgical Anatomy Course as useful and beneficial regarding understanding anatomical structure and relationship necessary for further surgical education. (Folia Morphol 2018; 77, 2: 279-285)

Key words: human anatomy course, surgery, learning of anatomy, Surgical Anatomy Course

\section{INTRODUCTION}

Gross anatomy is one of the fundamental, timehonoured medical courses [29]. However, the most effective teaching methodology of anatomy has not been definitively established. Some reports consid- ered traditional methods, e.g. human body atlases, cadaveric dissections, and prosections as the most appropriate $[22,23]$. At the same time, numerous modern techniques in teaching medicine, including computer-aided learning and simulation techniques,

Address for correspondence: K. Torres, MD, PhD, MBA, Department of Didactics and Medical Simulation, Chair of Human Anatomy, Medical University of Lublin, ul. Jaczewskiego 4, 20-094 Lublin, Poland, tel/fax: +48 8152888 18, e-mail: kamiltorres@wp.pl 
have been implemented [27]. Simulation has revolutionised teaching methodology in many fields of medicine including medical specialties which require practical skills, e.g. anaesthesia, surgery, gynaecology, cardiology $[7,20]$.

Without a doubt, knowledge of gross anatomy is fundamental for medical students. Moreover, there is substantial evidence suggesting that a good understanding of anatomy is essential for safe medical practice, particularly for those intending a surgical career $[9,24]$.

In Poland, medical universities offer a 6-year medical programme. The last year is clinically-centered with practical training in the seven primary medical specialties (internal medicine, surgery, family medicine, gynaecology and obstetrics, rescue medicine, psychiatry) [16]. Usually, in most of the Polish universities, medical curricula are designed according to the Flexner's model and are subject-based, with the basic sciences (first two and a half year) separated from clinical training. Clinical rotations start from the sixth semester with an introduction to propaedeutics of internal medicine and surgery.

Gaps in the knowledge of basic sciences are reported by both medical students and clinical teachers. A report on the quality of teaching of medical students, by our University, showed problems with the transition between basic and clinical sciences [19]. A Survey performed at our university by Staśkiewicz et al. [25] reported that students' anatomical knowledge, as assessed by teachers in clinical hospitals, was poor. Our local observations are in agreement with Waterston et al. [28] who found that the anatomy course seemed to prepare students incompletely for clinical sciences.

In response to the low retention of anatomical knowledge presented by medical students starting the clinical rotations, our team developed a Surgical Anatomy Course (SAC) as a novel educational tool with a primary aim to form a bridge between basic and clinical sciences and to facilitate the transition between theoretical and practical thinking.

The objective of the present study is to present a description of a SAC and the result of the survey aimed to investigate the importance and usefulness of the SAC among participants as well as their satisfaction after taking the course. The SAC was developed as a part of the project aimed to modernise the methodol-
Table 1. Surgical Anatomy Course' modules and theirs contents

\begin{tabular}{ll}
\hline Module & Content \\
\hline A & Bile tracts anatomy and laparoscopic cholecystectomy \\
B & $\begin{array}{l}\text { Anatomy of the anterolateral abdominal wall and basics } \\
\text { of plastic repair of an umbilical hernia }\end{array}$ \\
C & $\begin{array}{l}\text { Anatomy of the intestines and basics of gastric and } \\
\text { bariatric surgery }\end{array}$ \\
D & $\begin{array}{l}\text { Anatomy of the pelvis and basics of sigmoidectomy and } \\
\text { hysterectomy }\end{array}$ \\
\hline
\end{tabular}

ogy of teaching anatomy at our University. The project was supported by a grant from the European Union Human Capital Operational Programme 2007-2013 and was executed between 2011 and 2013.

\section{MATERIALS AND METHODS}

Training format and settings

The Department of Anatomy of our University, Poland introduced the SAC to the medical curriculum in October 2011 as a form of modern teaching methodology. The 12-h SAC was designated as four-module course for $4^{\text {th }}$ - and $5^{\text {th }}$-year medical students (Table 1 ).

Each module included a lecture based on the clinical case, the simulation training performed on the simulator (Simbionix LAB Mentor simulator), and the simulation of laparoscopic column usage (Karl Storz) based on cadaveric dissections. When writing the course curriculum, authors took into consideration the most frequent diseases treated surgically and tried to combine both the knowledge of human anatomy and surgical procedures. Such fusion of theory and practice helps to introduce the diagnostic and therapeutic procedures. Each module included final knowledge assessment. The anatomical structures and surgical procedures discussed during the SAC are presented in Table 2.

At the end of the course, each student was obligated to take the objective structured clinical exam (OSCE) and recognise ten anatomical structures and demonstrate skills in usage of laparoscopic tools. Anatomical structures were related to the: (i) blood supply of the stomach and liver, (ii) ligaments of the liver, (iii) bile ducts' system, (iv) antero-lateral abdominal wall, and (v) large intestine. Laparoscopic skills included camera manipulation, grasping and cutting, translocation of the object, and eye-hand coordination. Laparoscopic tasks were performed on the simulator (Simbionix LAB Mentor simulator). 
Table 2. Anatomical structures and principles of surgical procedures discussed during Surgical Anatomy Course

\begin{tabular}{|c|c|}
\hline \multicolumn{2}{|l|}{ Module A } \\
\hline Surgical anatomy & $\begin{array}{l}\text { Lobes and segments of the liver, gallbladder biliary tracts, pancreas, lesser omentum, duodenum, proper hepatic artery, } \\
\text { cystic artery, portal vein, Calot's triangle }\end{array}$ \\
\hline Basics of surgery & $\begin{array}{l}\text { Endoscopic retrograde cholangiopancreatography, laparoscopic cholecystectomy: Veress needle, trocars, pneumoperitoneum, } \\
\text { laparoscopic camera, laparoscopic tools }\end{array}$ \\
\hline \multicolumn{2}{|l|}{ Module B } \\
\hline Surgical anatomy & $\begin{array}{l}\text { Antero-lateral abdominal wall, umbilical folds, inguinal canal, Hasselbach triangle, direct and indirect inguinal hernias, } \\
\text { Spigelian, umbilical hernias }\end{array}$ \\
\hline Basics of surgery & Lichtenstein surgery \\
\hline \multicolumn{2}{|l|}{ Module C } \\
\hline Surgical anatomy & $\begin{array}{l}\text { Stomach, duodenum, jejunum, ileum, coeliac trunk, superior mesenteric artery, greater omentum, spleen, splenic artery } \\
\text { and vein, vagus nerves }\end{array}$ \\
\hline Basics of surgery & Gastrectomy, sleeve gastrectomy, gastric by-pass \\
\hline \multicolumn{2}{|l|}{ Module D } \\
\hline Surgical anatomy & $\begin{array}{l}\text { Colon, rectum, uterus, ovaries, vagina, ureters, inferior mesenteric artery, common iliac arteries, internal and external iliac } \\
\text { arteries, Douglas pouch }\end{array}$ \\
\hline Basics of surgery & Sigmoidectomy, hysterectomy \\
\hline
\end{tabular}

\section{The SAC evaluation}

Before and after the SAC, students were asked to take part in a survey to assess both the expectations and assessment of the course. The original survey was distributed in the Department of Anatomy directly after completing the course. The participation in the study was voluntary, and all collected data was anonymous.

Two anatomists and general surgeons reviewed the survey for its relevance and validity. The survey consisted of open-ended and multiple-choice questions with 6-point Likert scale (1 - totally not confident, 2 - mostly not confident, 3 - not confident, 4 - confident, 5 - mostly confident, 6 - totally confident). All SAC participants completed a survey. The survey included three sections: 1 - personal data (age, gender, study year), future specialisation, and self-evaluation of academic achievements; 2 - the evaluation of the course schedule and faculty; 3 - the assessment of student satisfaction with the course.

\section{Statistical analysis}

Data of the first section of the survey were presented as percentages of total participants while the data of the second and third parts were shown as means \pm standard deviation (SD).

\section{RESULTS}

A total of 314 medical students of our University attended the SAC and took part in the survey. The mean age of participants was 23.87 years and ranged from 23 to
Table 3. Experience with surgical classes and techniques reported by students taking Surgical Anatomy Course

\begin{tabular}{lc}
\hline Students' declaration & Percentage \\
\hline Participation in surgical classes & $84.05 \%$ \\
Contact with laparoscopic techniques & $69.20 \%$ \\
Contact with surgical instruments & $29.80 \%$ \\
Contact with laparoscopic camera & $12.55 \%$ \\
Contact with surgical tools and laparoscopic camera & $22.45 \%$ \\
Contact with simulation techniques & $2.75 \%$ \\
\hline
\end{tabular}

25 years. Female and male students constituted $61.55 \%$ and $38.45 \%$, respectively (female:male $=193: 121$ ).

Analysis of the students' experience with surgical classes and contact with surgical instruments (Table 3 ) showed that most of the participants took surgical classes and heard about laparoscopic techniques. Only a few students reported contact with simulation technology as a teaching method.

Analysis of the $2^{\text {nd }}$ part of the questionnaire regarding schedule and faculty of the SAC showed very high evaluation scores among students after completing the course (Fig. 1).

In the next part of the survey, students were asked to evaluate their satisfaction with the course. The results revealed very high scores in all assessed aspects of the course (Fig. 2).

Analysis of the students' answers concerning the content of modules of the SAC (Table 4) showed that 


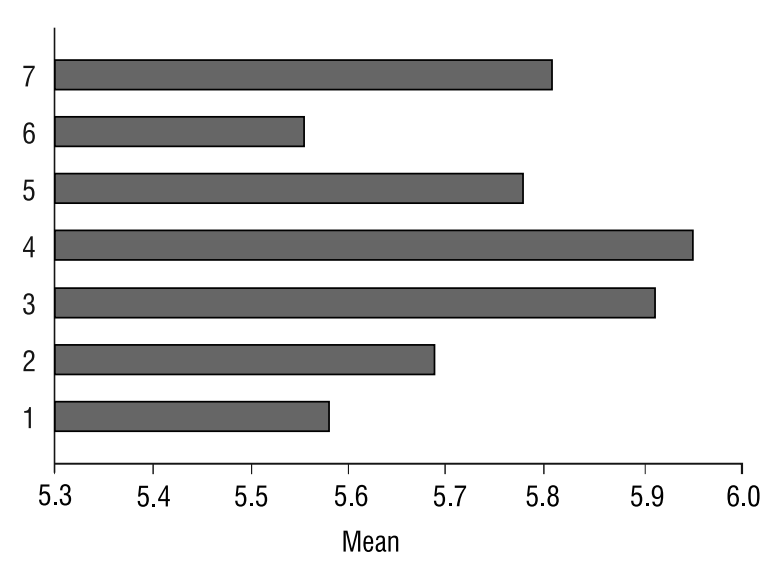

Figure 1. Scores of students' evaluation of the Surgical Anatomy Course schedule and faculty. 1 - goals of the course were well presented; 2 - content of the classes were compatible with the goals of the course; 3 - teachers were well prepared; $4-$ teachers took students seriously; 5 - summary of the class well organised; 6 - clinical cases presented during the class were well selected; 7 - equipment used during the classes was in good condition.

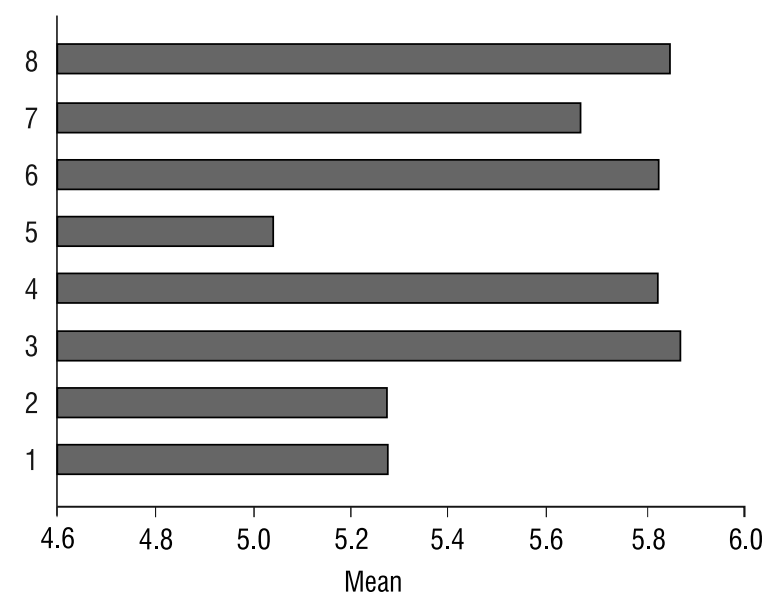

Figure 2. Scores of students' satisfaction with the Surgical Anatomy Course (SAC). 1 - feel comfortable during cadaver dissection; 2 - feel good prepared for simulation training; 3 - satisfaction with the SAC; 4 - readiness to recommend the SAC to other students; 5 - developed the ability to teamwork; 6 - willingness to participate in simulation exercises in the future; 7 -goals of the course achieved; 8 - SAC was valuable. the most interesting module was module A. Module A also obtained the highest satisfactory score among participants.

Most students (78.9\%) completing the SAC suggested the course should be introduced to the curriculum as an obligatory course for the medical students. Additionally, SAC is believed to support the traditional surgical classes by $86.4 \%$ of students while $99.1 \%$ of participants declared the course reviewed and improved anatomical knowledge and strengthened students' confidentiality and facilitated understanding and taking surgical rotations. The most popular students' comments concerning the course were presented in Table 5 .

At the end of the course each student was obliged to recognise 10 anatomical structures and demonstrate skills in usage of laparoscopic tools. The mean percentage of correct answers was 95\% for both theoretical and practical exam. Manipulation of laparoscopic camera was performed correctly by $92 \%$ of students. $94 \%$ of students could manipulate the laparoscopic tools while all participants finished successfully object translocation.

\section{DISCUSSION}

The study evaluated the innovative simulationbased SAC introduced at our University.

The first part of the assessment included students' experience in participation in surgical classes, contact with laparoscopic techniques, usage of surgical instruments and laparoscopic camera as well as simulation techniques before taking the SAC. The experience of most students in analysed areas was indigent; report showed moderate students' contact with laparoscopic techniques, instruments and simulation-based education. It could be explained by the fact that students during clinical rotations are more observers than active participants and the low popularity of simulation-based methods and little knowledge about this teaching methodology among Polish teachers, respectively.

Table 4. The percentage of students interested in Surgical Anatomy Course' modules and the mean value of the students' satisfaction of modules assessed in 6-point Likert scale

\begin{tabular}{lcc}
\hline Module & Percentage & Mean \pm standard deviation \\
\hline A - Bile tracts anatomy and bases of laparoscopic cholecystectomy & $35.6 \%$ & $5.7 \pm 0.55$ \\
B - Anatomy of the anterolateral abdominal wall and basics of plastic repair of inguinal hernia & $13.5 \%$ & $5.64 \pm 0.56$ \\
C - Anatomy of the intestines and basics of gastric and bariatric surgery & $32.1 \%$ & $5.65 \pm 0.59$ \\
D-Anatomy of the pelvis and basics of sigmoidectomy and hysterectomy & $18.8 \%$ & $5.66 \pm 0.58$ \\
\hline
\end{tabular}


Table 5. Students' comments on the Surgical Anatomy Course (SAC) grouped according to the topic

\begin{tabular}{|c|c|}
\hline Topic & Comments \\
\hline \multirow[t]{3}{*}{ The actuality of course } & All SAC modules were demonstrated on the same high level and presented the most common clinical cases. \\
\hline & Module A was the most interesting because as it presented case common in daily medical practice. \\
\hline & $\begin{array}{l}\text { The most curious was module } C \text { because hernias are frequent and is worth to know how hernias should be diagnosed } \\
\text { and treated. }\end{array}$ \\
\hline \multirow[t]{3}{*}{ Elements of anatomy } & $\begin{array}{l}\text { Module B was the most important because I finally understood abdominal cavity anatomy and topography what was } \\
\text { tough after 1-year gross anatomy course. }\end{array}$ \\
\hline & Module B helped me to refresh and improve knowledge acquired before. \\
\hline & Cadaver simulation reflected faithfully and vividly human anatomy. \\
\hline $\begin{array}{l}\text { Theory and practice } \\
\text { combination }\end{array}$ & The most interesting was the composition of theoretical knowledge with simulator training skills on cadaver simulation. \\
\hline \multirow{5}{*}{$\begin{array}{l}\text { Teamwork skills learned } \\
\text { during the course }\end{array}$} & This programme taught me teamwork and communication skills what is found very important. \\
\hline & It was the first time when I felt how to make my decision and cooperate with a medical team in operating theatre. \\
\hline & All the modules were absorbing and gave me an opportunity to train manual skills. \\
\hline & I could learn how to use surgical tools and cameras precisely on simulators. \\
\hline & It was a great practice of hernias palpate examination. \\
\hline \multirow[t]{3}{*}{ Surgical techniques } & We could see modern surgical techniques, e.g. gastrectomy with staplers' usage. \\
\hline & $\begin{array}{l}\text { Module A was the most curious because presented interesting clinical cases and medical tips like preparing } \\
\text { the surgical area. }\end{array}$ \\
\hline & Module A seemed to be the best because it was the first time when I saw surgical tools. \\
\hline \multirow[t]{5}{*}{ Programme and faculty } & I was positively surprised of the programme mode. \\
\hline & Module A impressed me so much that I am looking forward to seeing the next module. \\
\hline & Lecture based on clinical cases was interesting; simulation was modern teaching methodology. \\
\hline & Clinical case visualisation consolidated the knowledge. \\
\hline & All the modules were fantastic and prepared in a very professional way. \\
\hline \multirow{2}{*}{$\begin{array}{l}\text { Suggestions for course } \\
\text { improvement }\end{array}$} & The script could be helpful; however, labs could be longer with a break in the meantime to assimilate new knowledge. \\
\hline & $\begin{array}{l}\text { The programme like this should last longer; the way of teaching encourages attaining new information and stimuli } \\
\text { development. }\end{array}$ \\
\hline
\end{tabular}

A very high score was given to the SAC in both general impression and the triple-steep structure. Moreover, the highest graded part of the course was cadaver dissection which was additionally performed with the presentation of surgical procedures. According to the students' commentaries, cadaver dissection was essential in understanding the anatomy, reflected faithfully and vividly human anatomy, and created the possibility to explore anatomical structures in more detailed manner. Our results are comparable with the opinion that cadaveric dissection increases the participant' confidence and brings more profits when it is clinically oriented [21]. The chance to perform a controlled dissection in a human body without bleeding was postulated as the most significant advantage of anatomy training [13]. The implementation of cadaveric dissection to the course' structure provides quasi-real-life conditions, supports understanding of human body, and significantly supplement the theoretical knowledge gained with textbooks, atlases, or lecture notes. However, cadaver dissection has also a psychological aspect. Contact with the cadaver is a stressful experience for most of the students. The students' behaviour in the dissection room depends on their emotional status and teacher attitude [1]. Most commonly the environment of the dissection rooms might lead to various symptoms, e.g. nausea and fear [5]. The results of our study showed the students felt comfortable during dissection. Thus the teacher has an enormous role to create the positive atmosphere enhancing the learning process.

The Internal Report on the Quality of Education performed in our University revealed the necessity of 
implementation of practical and hands-on courses to the medical curriculum. More than half of respondents indicated the number of practical courses is inadequate [19]. It is crucial that practical experience supplements the traditional education process and increases the skills needed to enter the job market after graduate. Educational studies reported that positive students' evaluation of hands-on courses, concluding such courses are highly effective in facilitating learning process $[4,26]$. It seems that single teaching tool cannot meet curriculum requirements. Probably the best approach which guarantees high knowledge retention is a combination of multiple teaching methodologies with pedagogical resources to complement one another [11].

A strong emphasis on procedural skills in medical professions requires the continuous training under real-life conditions [6]. Simulation-based training gives a great opportunity to both learn and improve practical skills $[2,8]$. Our students declared willingness to participate in simulationbased training in the future and are conscious that during professional life they will need a continuous training to gain knowledge, skills, and competencies. According to Marks [18], traditional teaching in medical science requires constant innovations to face a challenge of developing knowledge, procedures, and technology.

The effectiveness of the simulation-based training results from the role of an instructor who aims to facilitate the education and training and assess performance and competency of both individual learners and team [10]. Teacher's preparation and attitude to students during SAC were evaluated with very high score, thus it shows that students prefer the facilitating model of mentoring than traditional. Simulation trainer establishes communication rules, decision-making norms, creates an area for discussion, negotiation, and debate. Such model of learning meets the highest students' expectations and is widely accepted [15].

Medical students should be creative and able to work as a team [3]. Our students declared great usefulness of the SAC in developing the ability to work in a team and commented that SAC created the opportunity to make their decision and take the responsibility. Team training conducted with simulation-based exercises results in a significant improvement in team performance in complicated, medical procedures $[14,17]$. Simulation-based team training is superior in improving communication skills and team building competencies to traditional methods of teaching [12].

\section{CONCUSSIONS}

In conclusion, the SAC was positively evaluated by the students as innovative and useful. The course combining the practical learning of anatomy and surgical-based approaches is beneficial for the understanding of anatomical structure and relationships between them, especially for further surgical education. The long-term effect of the SAC was the implementation of the course into the medical curriculum for third-year medical students as an obligatory course.

\section{Funding}

This work has been supported by a Medical University scientific grant DS205 for Kamil Torres.

\section{REFERENCES}

1. Arráez-Aybar LA, Castaño-Collado G, Casado-Morales MI. Dissection as a modulator of emotional attitudes and reactions of future health professionals. Med Educ. 2008; 42(6): 563-571, doi: 10.1111/j.1365-2923.2008.03079.x, indexed in Pubmed: 18452515.

2. Bond WF, Deitrick LM, Arnold DC, et al. Using simulation to instruct emergency medicine residents in cognitive forcing strategies. Acad Med. 2004; 79(5): 438-446, indexed in Pubmed: 15107283.

3. Banga FR, Truijens SEM, Fransen AF, et al. The impact of transmural multiprofessional simulation-based obstetric team training on perinatal outcome and quality of care in the Netherlands. BMC Med Educ. 2014; 14: 175, doi: 10.1186/1472-6920-14-175, indexed in Pubmed: 25145317.

4. Brown B, Adhikari S, Marx J, et al. Introduction of ultrasound into gross anatomy curriculum: perceptions of medical students. J Emerg Med. 2012; 43(6): 1098-1102, doi: 10.1016/j.jemermed.2012.01.041, indexed in Pubmed: 22459597.

5. Cahill KC, Ettarh RR. Attitudes to anatomy dissection in an Irish medical school. Clin Anat. 2009; 22(3): 386-391, doi: 10.1002/ca.20777, indexed in Pubmed: 19280654.

6. Carr J, Deal AM, Dehmer J, et al. Who teaches basic procedural skills: student experience versus faculty opinion. J Surg Res. 2012; 177(2): 196-200, doi: 10.1016/j. jss.2012.05.084, indexed in Pubmed: 22818085.

7. Cant RP, Cooper SJ. Simulation in the Internet age: the place of web-based simulation in nursing education. An integrative review. Nurse Educ Today. 2014; 34(12): 1435-1442, doi: 10.1016/j.nedt.2014.08.001, indexed in Pubmed: 25156144.

8. Cohen AR, Lohani S, Manjila S, et al. Virtual reality simulation: basic concepts and use in endoscopic neurosurgery training. Childs Nerv Syst. 2013; 29(8): 1235-1244, doi: 10.1007/s00381-013-2139-z, indexed in Pubmed: 23702736. 
9. Craig S, Tait N, Boers D, et al. Review of anatomy education in Australian and New Zealand medical schools. ANZ J Surg. 2010; 80(4): 212-216, doi: 10.1111/j.14452197.2010.05241.x, indexed in Pubmed: 20575945.

10. Dieckmann P, Molin Friis S, Lippert A, et al. The art and science of debriefing in simulation: Ideal and practice. Med Teach. 2009; 31(7): e287-e294, indexed in Pubmed: 19811136.

11. Estai M, Bunt $S$. Best teaching practices in anatomy education: A critical review. Ann Anat. 2016; 208: 151-157, doi: 10.1016/j.aanat.2016.02.010, indexed in Pubmed: 26996541.

12. Fransen AF, van de Ven J, Merién AER, et al. Effect of obstetric team training on team performance and medical technical skills: a randomised controlled trial. Br J Obstet Gynaecol. 2012; 119(11): 1387-1393, doi: 10.1111/j.14710528.2012.03436.x, indexed in Pubmed: 22882714.

13. Fitzpatrick CM, Kolesari GL, Brasel KJ. Teaching anatomy with surgeons' tools: use of the laparoscope in clinical anatomy. Clin Anat. 2001; 14(5): 349-353, doi: 10.1002/ ca.1062, indexed in Pubmed: 11754223.

14. Grogan EL, Stiles RA, France DJ, et al. The impact of aviation-based teamwork training on the attitudes of health-care professionals. J Am Coll Surg. 2004; 199(6): 843-848, doi: 10.1016/j.jamcollsurg.2004.08.021, indexed in Pubmed: 15555963.

15. Harden RM, Crosby JR. The good teacher is more than a lecturer: The twelves roles of the teacher. AMEE Education Guide. 2000. No: 20.

16. Janczukowicz J. Medical education in Poland. Med Teach. 2013; 35(7): 537-543, doi: 10.3109/0142159X.2013.789 133, indexed in Pubmed: 23631409.

17. Kirkpatrick D. Evaluating training programmes; the four levels. San Francisco, CA: Berrett-Kochler Publishers. 1994.

18. Marks SC. Information technology, medical education, and anatomy for the twenty-first century. Clin Anat. 1996; 9(5): 343-348, doi: 10.1002/(SICI)10982353(1996)9:5<343::AID-CA8>3.0.CO;2-D, indexed in Pubmed: 8842542.

19. MUL.Teaching methods preferences of students of MUL. Department of Education Quality Assessment. 2014.
20. Mileder LP, Urlesberger B, Szyld EG, et al. Simulation-based neonatal and infant resuscitation teaching: a systematic review of randomized controlled trials. Klin Padiatr. 2014; 226(5): 259-267, doi: 10.1055/s-0034-1372621, indexed in Pubmed: 25153910.

21. Mitesh Sharma M, Macafee D, Horgan AF. Basic laparoscopic skills training using fresh frozen cadaver: a randomized controlled trial. Am J Surg. 2013; 206(1): 23-31, doi: 10.1016/j.amjsurg.2012.10.037, indexed in Pubmed: 23623462.

22. Netterstrøm I, Kayser L. Learning to be a doctor while learning anatomy! Anat Sci Educ. 2008; 1(4): 154-158, doi: 10.1002/ase.31, indexed in Pubmed: 19177402.

23. Nnodim JO. Learning human anatomy: by dissection or from prosections? Medical Education. 1990; 24(4): 389-395, doi: 10.1111/j.1365-2923.1990.tb02456.x.

24. Peck $D$, Skandalakis JE. The anatomy of teaching and the teaching of anatomy. Am Surg. 2004; 70(4): 366-368, indexed in Pubmed: 15098794.

25. Staśkiewicz GJ, Walczak E, Torres K, et al. What do clinicians think of the anatomical knowledge of medical students? Results of a survey. Folia Morphol. 2007; 66(2): 138-142, indexed in Pubmed: 17594673.

26. Tshibwabwa ET, Groves HM. Integration of ultrasound in the education programme in anatomy. Med Educ. 2005; 39(11): 1148, doi: 10.1111/j.1365-2929.2005.02288.x, indexed in Pubmed: 16262819.

27. Torres K, Torres A, Pietrzyk L, et al. Simulation techniques in the anatomy curriculum: review of literature. Folia Morphol. 2014; 73(1): 1-6, doi: 10.5603/FM.2014.0001, indexed in Pubmed: 24590516.

28. Waterston SW, Stewart IJ. Survey of clinicians' attitudes to the anatomical teaching and knowledge of medical students. Clin Anat. 2005; 18(5): 380-384, doi: 10.1002/ ca.20101, indexed in Pubmed: 15971223.

29. Yammine K. The current status of anatomy knowledge: where are we now? Where do we need to go and how do we get there? Teach Learn Med. 2014; 26(2): 184-188, doi: 10.1080/10401334.2014.883985, indexed in Pubmed: 24702556 . 